\title{
The evolution of foreign exchange market based on European sovereign debt crisis
}

\author{
Mansooreh Kazemi Lari*, Maman Abdurachman Djauhari \\ Department of Mathematics, Faculty of Science, Universiti Teknologi Malaysia, 81310, \\ UTM, Johor Bahru, Malaysia \\ *Corresponding author E-mail:mansooreh_kazemilari@yahoo.com
}

\begin{abstract}
This study examined the network topology of international foreign exchange markets from 2009 to 2012 in terms of European sovereign debt crisis by using the minimum spanning tree (MST) approach. In the process, the time series evolution is analyzed in relation to the structure changes of MSTs during the crisis period. By deriving some notable changes in network feature, we compare their properties for two subdivided period of currency crisis.
\end{abstract}

Keyword: International foreign exchange market, European sovereign debt crisis, Minimum spanning tree.

\section{Introduction}

Currency markets which represent the most liquid and largest financial market are extremely important. This is because the power of a currency reflects the country's economic status, and its foreign exchange rate is representative of the political and economic balance of two countries. From a physical perspective, foreign exchange markets are typically open systems that have interactions with all kinds of financial information around the world, including price changes in other markets.

In financial markets, analysis of topology network provides efficient methods to describe the properties of a structure and is a widely used analytical tool. Practical usage of this tool was first introduced by Mantegna [1] which utilized the MST to analyze a currency's behavior and the properties of Forex (FX) markets. An example of this study is that done by McDonald et al. [2] which had developed a currency correlation network analysis of the FX market by using the MST method. Results indicated that MST can be used to identify the foreign exchange dynamics such as dependent and dominant currency structures. On the other hand, Mizuno et al. [3] analyzed the currency exchange rate and classified the currencies on a hierarchical taxonomy of currencies using the MST constructed according to the correlation coefficients. Meanwhile, Guillermo and Matesanz [4] constructed a MST of the FX network by dividing the FX markets into segments of countries from homogeneous geographical regions and to analyze a sample of FX data. Naylor et al. [5] created two currency networks to examine the topology evolution of networks by utilizing the MST. A set of FX was also analyzed by Kwapien et al. [6] to investigate the topology evolution of FX markets, and as in FX markets, different currencies can produce different MST structures. Moreover, Keskin et al. [7] also researched the usage of the MST and hierarchical tree tools on the topology of correlation networks. More lately, based on the MST technique, Jang et al. [8] examined the time series properties of FX markets in the history of currency crises. To study the topology of networks similarity in connection to the US subprime crises, Wang et al. [9] used a rather different style where a dynamic time warping technique was applied.

In previous studies, the time series properties of currency networks in relation to history of crises was investigated by examining the evolution of network before, during and after crises to analyze the structure changes. In this study, the network properties of the foreign exchange market is examined during the European sovereign debt crisis in two subperiods because it contains two stages: first period starts from the beginning the crisis from April 2009 until April 2010 and second period from May 2010 to September 2012 when the European crisis became widespread in most of the European countries.

Since sovereign debt crisis is one kind of currency crises, we analyze a set of FX rates of 48 major currencies in relation to European sovereign debt crisis and construct the MST of the currency network to research the topology evolution of FX markets during the European sovereign debt crisis. In section 2 and 3, we present the data set and the methodology. In Section 4, we construct the MST of FX networks derived from the entire set of data and give the main empirical 
results. Finally, we draw some conclusions.

\subsection{European sovereign debt crisis}

In recent decades, substantial changes in the structure of financial markets in the Eurozone system have taken place. Structural problem of Eurozone system resulted from a combination of complex factors such as the 2007-2012 global financial crises, international trade imbalances, the 2008-2012 global recessions.

The European sovereign debt crisis is an ongoing financial crisis that has made it difficult or impossible for some countries in the Euro area to repay or re-finance their government debt without the assistance of third parties. The European sovereign debt crisis started with the collapse of Iceland's banking system, and spread primarily to Greece, Ireland and Portugal. The debt crisis led to a crisis of confidence for European businesses and economies. Several European countries faced the collapse of financial institutions, high government debt and rapidly rising bond yield spreads in government securities. Most commentators trace the beginning of the European sovereign debt crisis from late 2009, when Greece revealed that its budget deficit. However, the real origins of the crisis can be traced to the very structures that govern Europe'sinstitutions and to the players that govern European institutions [10].

On 6 September 2012, the , the European Central Bank (ECB) also calmed the financial markets by announcing free unlimited support for all Eurozone countries involved in a sovereign state bailout/ precautionary programme [11].

\section{Data}

The study is implemented using foreign exchange rate of 48 major countries provided by Exchange Rate Service available online http://fx.sauder.ubc.ca/ at [12] the daily frequency. The daily close price observations start from April 2009 until September 2012, covering the time periods related to the European sovereign debt crisis because major economic turbulence occurred during this period. Table 1 presents currency symbols of 48 countries.

The foreign exchange rate is normally based on the US dollar. Nonetheless, it stated in connection to the Special Drawing Right (SDR), which is a possible claim on the freely usable currencies of the International Monetary Fund (IMF) to include the US dollar and avert exogenous factors from influencing the currency network. The combined value of a basket of major currencies used in international trade and finance is the value of SDR.

Table 1: Countries and their currencies symbols

\begin{tabular}{|c|c|c|c|c|c|}
\hline European Country & Currency & American Country & Currency & Asian Country & Currency \\
\hline Austria & ATS & Argentina & ARS & China & $\mathrm{CNY}$ \\
\hline Belgium & $\mathrm{BEF}$ & Brazil & BRL & Egypt & EGP \\
\hline British & GBP & Canada & CAD & India & INR \\
\hline Bulgaria & BGN & Chili & CLP & Indonesia & IDR \\
\hline Czech & $\mathrm{CZK}$ & Colombia & $\mathrm{COP}$ & Israel & ILS \\
\hline Europe & EUR & Jamaica & JMD & Japan & JPY \\
\hline France & FRF & Mexico & MXN & Kuwait & KWD \\
\hline Germany & DEM & Peru & PEN & Malaysia & MYR \\
\hline Greece & GRD & United States & USD & Philippines & PHP \\
\hline Iceland & ISK & & & Saudi Arabia & SAR \\
\hline Italy & ITL & & & Singapore & SGD \\
\hline Norway & NOK & & & South Korea & KRW \\
\hline Polish & PLN & & & Sri Lanka & LKR \\
\hline Russia & RUB & & & Taiwan & TWD \\
\hline Slovakia & SKK & & & Emirate & AED \\
\hline European Country & Currency & Pacific Ocean & Currency & Africa country & Currency \\
\hline Slovenia & SIT & Australia & AUD & South Africa & ZAR \\
\hline Spain & ESP & Fiji & FJD & & \\
\hline Sweden & SEK & New Zealand & NZD & & \\
\hline Swiss & $\mathrm{CHF}$ & & & & \\
\hline Turkey & TRY & & & & \\
\hline
\end{tabular}




\section{Methodology}

The methodology suggested by Mantegna [1] utilized Pearson correlation coefficient as vital input which quantifies the degree of similarity between all pairs of random variables. The Pearson correlation coefficient of the daily differences in the logarithm rate is applied in order to detect the topological arrangements of the currencies. The currencies are further classified based on the MST and in accordance to the correlation coefficients. MST is a kind of currency map and is helpful for understanding the network structure and properties of FX markets. Beneficial insights on the global structure of the financial data, particularly in the equity and exchange rate markets have been demonstrated with MST methodology $[1,2]$.

Since the work of Mantegna, the Pearson correlation is also used by Bonanno et al. [13] and many authors to analyze networks' property. To calculate the correlation coefficients between currencies, the daily rate change $R_{i}(t)$ at the time $t$ defined as:

$$
R_{i}(t)=\ln \left(P_{i}(t+1) / P_{i}(t)\right)
$$

Where $\mathrm{P}_{\mathrm{i}}(\mathrm{t})$ is the rate $i$ at the time $t$ and $i=1,2 \ldots, N$ (number of currencies). The correlation coefficient between currencies $i$ and $j$, is given by:

$$
\mathrm{C}_{\mathrm{ij}}=\frac{<\mathrm{R}_{\mathrm{i}} \cdot \mathrm{R}_{\mathrm{j}}>-<d R_{\mathrm{i}}><\mathrm{dR}_{\mathrm{j}}>}{\sqrt{\left(<\mathrm{dR}_{\mathrm{i}}^{2}>-<\mathrm{dR}_{\mathrm{i}}>^{2}\right)\left(<\mathrm{dR}_{\mathrm{j}}^{2}>-<\mathrm{dR}_{\mathrm{j}}>^{2}\right)}}
$$

Where $\left\langle d R_{i}>\right.$ is the statistical average of $\mathrm{dR}_{\mathrm{i}}(\mathrm{t})$ for $t$. By definition, $C_{i j}$ can change from -1 (completely anticorrelated) to 1 (completely correlated). When $\mathrm{C}_{\mathrm{ij}}=0$, the two currencies are uncorrelated.

Correlation coefficients between all pairs of currencies form a $N \times N$ matrix consist of $N(N-1) / 2$ correlation coefficient. This matrix is a symmetric matrix $C_{i j}=C_{j i}$ with $C_{i j}=1$ in the main diagonal. Based on correlation matrix, the mean correlation coefficients at time $t$ is defined as

$$
C^{t}=\frac{2}{N(N-1)} \sum_{i=1}^{N-1} \sum_{j=i+1}^{N} C_{i j}
$$

The time window width $t$ is about 250 trading days in one year, and the step length $\Delta \mathrm{t}$ is one week [14].

We convert the correlation matrix to the distance matrix $D$ to construct a currency minimum spanning tree (MST) to understand more behavior of given currencies in the network. The MST forms taxonomy for a topological space of the $N$ rates. The MST is a tree having $N-1$ edges that minimize the sum of the edge distances in a connected weighted graph of the $N$ rates. The edge distances satisfy the following three axioms of a Euclidean distance:

(i) $\quad d_{i j}^{t}=0$ if and only if $i=j$,

(ii) $\quad d_{i j}^{t}=d_{j i}^{t}$

(iii) $\quad d_{i j}^{t} \leq d_{i k}^{t}+d_{k j}^{t}$.

Here $d_{i j}^{t}$ expresses a distance for a pair of the rate $i$ and the rate $j$. We need Euclidean distances between the rates in order to construct the MST. However, the correlation coefficient $C_{i j}$ does not satisfy the axioms. We can convert the correlation coefficient by appropriate functions so that the axioms can be applied [15]. So, appropriate functions is

$$
d_{i j}^{t}=\sqrt{2\left(1-C_{i j}\right)}
$$

$d_{i j}^{t}$ is the edge distance between nodes (currencies) $i$ and $j$ at time $t$. By examining the normalized tree length at time $t$, $L(t)$, which is the average distance of edges in MST defined below, the property of the foreign exchange market can be observed.

$$
L(t)=\frac{1}{N-1} \sum_{d_{i j}^{t} \in \Theta} d_{i j}^{t}
$$

Where $\Theta$ is the set of edges. Here $\mathrm{d}_{\mathrm{ij}}^{\mathrm{t}}$ is the distance between the points presented in MST and $N-1$ is the number of edges [16]. Onnela et al. [17] presented the mean occupation layer to measure changes in the density of MST for the central point at time $t$. Is given by: 


$$
\mathrm{L}\left(\mathrm{v}_{\mathrm{c}}\right)=\frac{1}{\mathrm{~N}} \sum_{\mathrm{i}=1}^{\mathrm{N}} \operatorname{Lev}\left(\mathrm{v}_{\mathrm{i}}\right)
$$

where $\operatorname{Lev}\left(\mathrm{v}_{\mathrm{i}}\right)$ is the level of a node $\mathrm{v}_{\mathrm{i}}$ in terms of degree centrality in this study. Degree centrality describes the degree of importance of information for each node according to the idea that more important nodes are more active and therefore should have more connections. The degree centrality measure of a node (currency) $v$ is calculated using the following formula:

$$
C_{D}(v)=\sum_{j=1}^{n} \operatorname{degree}(v) /(N-1)
$$

\section{Result and discussion}

In this section, the time series properties of the currency network will be examined in relation to the European sovereign debt crisis. At first, the period of crisis from April 2009 to September 2012 is subdivided into two sub-periods: First period starts from April 2009 until April 2010 and second period from May 2010 to September 2012 when the European crisis became widespread in most of the European countries. Then, the network evolution of foreign exchange market will be analyzed by comparing the structural changes in these two periods.

To study the topology evolution of FX markets, we select three network property measures (normalized tree length, mean correlation coefficient and mean occupation layer). The mean correlation coefficient with step length $\Delta t=1$ week between all currencies of FX market from 2009 to 2012 is presented in Fig. 1.

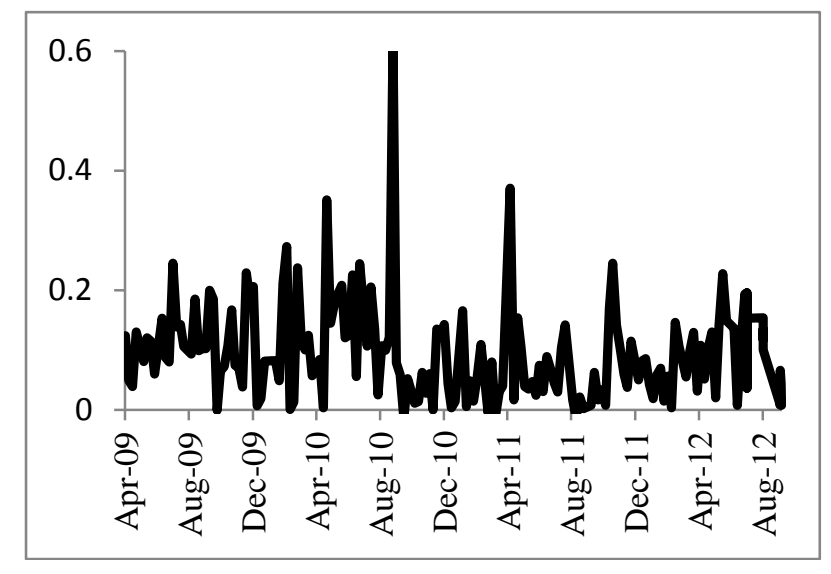

Fig. 1: Mean of correlation coefficients as a function of $\mathrm{t}$ for $\Delta \mathrm{t}=1$ week

According to changes in mean correlation coefficient presented in Fig. 1, as we expect, the values of mean correlation coefficient are low during the crisis period. Besides, in the first period (2009-2010), the fluctuation of mean correlation (between 0.08 and 0.15) is not significant. However, in second Period (2010-2012), there are two wave peaks, which mean correlation coefficient increased in August 2010 and March 2011 then dropped rapidly for a short time.

The European sovereign debt crisis started in 2009 and became widespread from 2010-2012, Thus; this claim was substantiated by our results. Furthermore, the results also give proof to support the subdivision in two periods.

Table 2 organized to compare tree network properties including: normalized tree length, mean correlation coefficient and mean occupation layer for two sub-period of crisis.

Table 2: Normalized tree length, Mean Correlation coefficient and Mean occupation layer in the first and second Period of crisis

\begin{tabular}{lll}
\hline & $2009-2010$ & $2010-2012$ \\
\hline Normalized tree length & 0.676 & 0.707 \\
Mean correlation coefficient & 0.122 & 0.072 \\
Mean occupation layer & 0.191 & 0.170 \\
\hline
\end{tabular}


As a result of Table 2, the normalized tree length has increased in the second period of crisis. It is also seen that the mean of correlation coefficient between currencies decreased while the normalized tree length increased in this period. However, in both periods, the value of mean correlation and mean occupation layer are low because of the period of European sovereign debt crisis. But, during the second period of crisis, the value of mean occupation layer is smaller compared to the first period, which shows that the market structure of the FX network in first Period is correlated than second Period.

To study the topology evolution of the currency network, we present the MSTs. Two networks of 48 currencies is constructed using Kruskal's algorithm. Fig. 2 and Fig. 3 show the minimum spanning tree for $\mathrm{N}=48$ currencies in two sub-periods of crisis: first period from April 2009 to April 2010 and second period from May 2010 to September 2012. Size of nodes represents the score of degree centrality measure and the rank of importance.

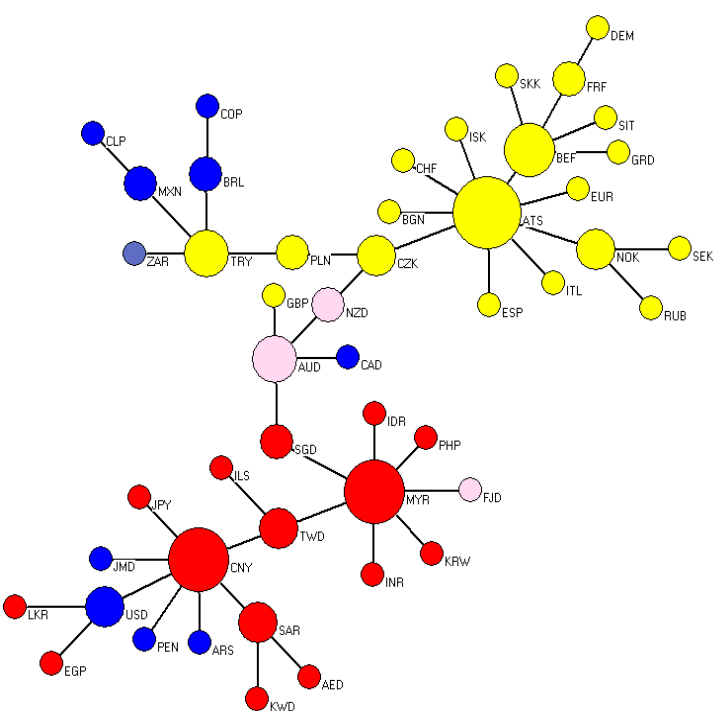

Fig. 2: Minimum spanning tree based on degree centrality in first period (April 2009- April 2010)

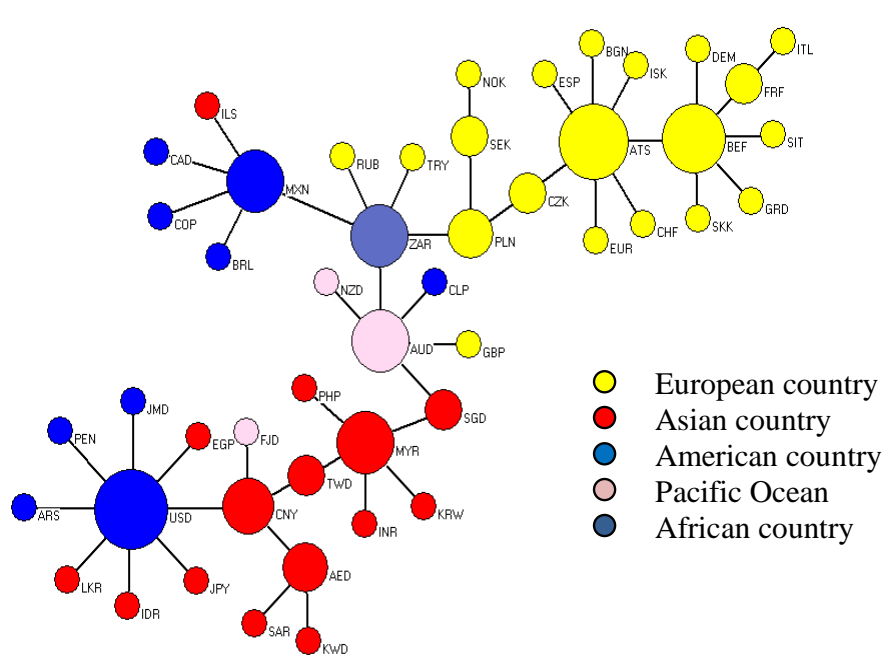

Fig. 3: Minimum spanning tree based on degree centrality second (May 2010-September 2012)

Generally, Fig. 2 and Fig. 3 indicate that the MST complemented well with corresponding countries from the same geographical regions in the world such as Asia and Europe. European countries are linked together with other regional countries. EUR (Europe) that is a dominant international currency is at the lowest level of degree centrality in both periods of crisis.

In the first period of crisis, as shown in Fig. 2, ATS (Austria), CNY (China) and MYR (Malaysia) are central currencies in the currency network. ATS (Austria) acts the most central position in the MST network, and other European currencies are connected to it. However, in the second period, as drawn in Fig. 3, ATS(Austria) losing the central position and USD occupies as central positions in the MST network whereas European currencies are still in lowest level and linked to ATS. CNY (China) and MYR (Malaysia) also as two central currencies in first period lost the most centrality. TRY (Turkey) and NOK (Norway) are other European currencies that lost centrality measures.

\section{Conclusion}

This paper has concentrated on a network based on study of currency crises in foreign exchange markets. We presented the topology of similarity networks among 48 chief currencies using the MST technique in two durations of European sovereign debt crisis. Then, by deriving some useful observations, we analyzed the topology evolution of FX markets in terms of the changes of the MSTs.

When the European crisis became prevalent in most of the European countries, the mean correlation coefficient reduced whereas the normalized tree length increased in the second period. Particularly, the mean correlation coefficient has low values during the crisis period.

Our result shows that currency networks have several notable alterations during the European sovereign debt crisis in comparing between first period and second period of crises. We find that the MSTs matched nicely with the geographical regions of corresponding countries in both periods of crises. ATS (Austria) lost the central position in second period and USD became central currency in the second period of crisis. European currencies also moved away from central currency (USD) in the second period and EUR which is a dominant world currency remained at the lowest level of degree centrality among European currencies in both periods of crisis. 
The outcomes of this study could be developed into research for forecasting and signaling disturbances adversely affecting the stability of the physical world; and giving sufficient time to prepare resources and response actions to minimize the impact on the stability of the physical world for financial crises.

\section{Acknowledgements}

This research is sponsored by the Malaysian Ministry of Higher Education and Universiti Teknologi Malaysia for their financial funding through FRGS 4F013. The authors gratefully acknowledge that sponsorship and Universiti Teknologi Malaysia for the support and facilities during given this research.

\section{References}

[1] R.N. Mantegna,"Hierarchical structure in financial markets", The European Physical Journal B-Condensed Matter and Complex Systems, Vol.11, (1999), p. 193-197.

[2] M. McDonald, O. Suleman, S. Williams, S. Howison and N.F. Johnson,'Detecting a currency's dominance or dependence using foreign exchange network trees", Physical Review E, Vol. 72, No. 4, (2005), p. 046106.

[3] T. Mizuno, H. Takayasu and M. Takayasu,"Correlation networks among currencies", Physica A: Statistical Mechanics and its Applications, Vol.364, (2006), pp. 336-342.

[4] J.O. Guillermo and D. Matesanz,"Cross-country hierarchical structure and currency crises”, International Journal of Modern Physics C, Vol. 17, (2006), pp. 333-341.

[5] M.J. Naylor, L.C. Rose and B.J. Moyle,’Topology of foreign exchange markets using hierarchical structure methods", Physica A: Statistical Mechanics and its Applications, Vol.382, (2007), pp.199-208.

[6] J. Kwapien, S. Gworek and S. Drozdz,"Structure and evolution of the foreign exchange networks", arXiv preprint arXiv: 0901.4793, Vol.40, (2009), pp. 175-194.

[7] M. Keskin, B. Deviren and Y. Kocakaplan,"Topology of the correlation networks among major currencies using hierarchical structure methods". Physica A: Statistical Mechanics and its Applications, Vol.390, No.4, (2011), pp. 719-730.

[8] W. Jang, J. Lee and W. Chang,"Currency crises and the evolution of foreign exchange market: Evidence from minimum spanning tree", Physica A, Vol. 390, (2011), pp. 707-718.

[9] G.J. Wang, C. Xie, F. Han and B. Sun,’Similarity measure and topology evolution of foreign exchange markets using dynamic time warping method: Evidence from minimal spanning tree", Physica A: Statistical Mechanics and its Applications, Vol.391, (2012), pp. 4136-4146.

[10] P.R. Lane,"The European sovereign debt crisis", The Journal of Economic Perspectives, Vol.26, No.3, (2012), pp. 49-67.

[11] D. Blenck, H. Hasko, S. Hilton and K. Masaki,"The main features of the monetary policy frameworks of the Bank of Japan", the Federal Reserve and the Eurosystem, BIS Papers, Vol.9, (2013), pp. 23-56.

[12] W. Antweiler, Pacific Exchange rate, fx.sauder.ubc.ca/.

[13] G. Bonanno, F. Lillo and R.N. Mantegna,"High-frequency cross-correlation in a set of stocks", Quantitative Finance, Vol.1, (2001), pp. 96104.

[14] H. Situngkir and Y. Surya,"On Stock Market Dynamics through Ultrametricity of Minimum Spanning Tree”, (2005).

[15] R.N. Mantegna and H.E. Stanley," Introduction to econophysics: correlations and complexity in finance", Cambridge university press, ISBN13: 978-0521620086, (2000).

[16] J.P. Onnela, A. Chakraborti, K. Kaski and J. Kertesz,"Dynamic asset trees and portfolio analysis", The European Physical Journal BCondensed Matter and Complex Systems, Vol. 30, No. 3, (2002), pp. 285-288.

[17] J.P. Onnela, A. Chakraborti and K. Kaski,'Dynamics of market correlations: Taxonomy and portfolio analysis", Physical Review E, Vol.68, (2003), pp. 056110(1)-056110(12). 